\title{
Memórias de Pesquisa: a experiência de uma psicóloga no interior de uma prisão feminina
}

\section{Rosalice Lopes*}

Como psicóloga e pesquisadora de questões relacionadas às prisões há 22 anos considero um grande desafio tentar organizar algumas poucas reflexões que possam levar o leitor a se interessar e conhecer aquilo que muitos agentes de segurança penitenciária descrevem como "o outro mundo das prisões".

É impossível negar - quer na condição de interno quer de trabalhador - os múltiplos efeitos que as prisões produzem às subjetividades que lá se encontram na condição de "encarcerados". Como tantos que lá estiveram durante algum tempo, pude viver e sentir mudanças na forma de "ver" e "pensar" as prisões. Muito ainda existe para ser conhecido, mas deixo aqui registradas algumas de minhas considerações.

Não vou, nestas poucas páginas, desgastar o leitor apresentando idéias sobre a natureza e a função social das prisões. Autores, como Goffman (1965, 1971), Foucault $(1977,1984,1996)$, Rocha (1994) e Salla (1999), apresentaram visões contundentes sobre o poder que essas instituições têm de restringir a experiência humana a um mínimo quase insuportável promovendo um trágico fim àqueles que se revoltam ou enlouquecem.

Embora seja necessário admitir que, em se tratando de seus mecanismos disciplinadores e de sua visão focada sobremaneira na segurança, as prisões produzem em seus internos - quer sejam
* Centro Universitário de Santo André - UNIA. 


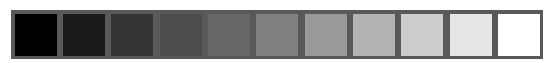

Lopes, R. Memórias de Pesq.: a exp. de uma psicóloga no interior de uma prisão feminina

homens quer mulheres - efeitos e sentimentos análogos, minha proposta neste espaço é apresentar a descrição de uma unidade prisional feminina.

Pretendo, em primeiro lugar, produzir reflexões na direção do que afirmam pesquisadoras das áreas jurídica e sociológica, na América do Sul e do Norte, além da Europa, as quais evidenciam o descaso na consideração das diferentes necessidades das mulheres presas e denunciam a condição de "invisibilidade" em que elas se encontram no âmbito das políticas públicas voltadas ao setor (FERNANDÉZ, 1995, GRAZIOSI, 1999, PARENT,1986, SMAUS, 1999).

Em segundo lugar, pretendo levar o leitor a buscar um maior esclarecimento sobre as diferentes concepções sobre a imputabilidade de homens e mulheres, as quais decorreram de concepções distintas sobre o sexo e gênero e acabaram por se refletir tanto na forma como as penas foram aplicadas às mulheres acusadas quanto nas condições oferecidas para que elas, efetivamente, cumprissem suas penas (LAQUEUR, 2001, ROSALDO; LAMPHERE, 1979, SAFFIOTI, 1992, 1994).

A história do encarceramento de mulheres no Brasil conta com poucos registros. Todavia, naqueles disponíveis fica evidente que $o$ sentido da pena tem reproduzido, historicamente, a mesma

1 Segundo informações da Secretaria da Administração Penitenciária - SAP, os Centros de Ressocialização Femininos teriam uma proposta distinta no que se refere às mulheres, mas até o momento da redação deste texto não tive oportunidade de visitálos. Porém, de outro lado, informações de funcionários do sistema prisional dão notícia de que as mulheres presas da Capital de São Paulo serão, em sua totalidade, encaminhadas para o historio prédio da Penitenciária do Estado, uma unidade pensada para homens. orientação de outros países, ou seja, o encarceramento de pobres e a reprodução do domínio masculino (BIERRENBACH, 1998, GRAZIOSI, 1999, ARÚS, 1995, SALLA, 1999).

Em nosso país inexistem presídios construídos especialmente para mulheres ${ }^{1}$ e muitos dos que elas ocupam surgiram após adaptações feitas em prédios destinados a outros fins.

As prisões femininas - embora diferentes, em sua dinâmica, das prisões masculinas - foram idealizadas como "prisões de homens" e seguem, em muitos sentidos, o espírito das prisões masculinas. Não existir um presídio "pensado" para mulheres talvez reflita a obscura concepção de que as mulheres criminosas são mais inferiores que os já inferiorizados homens que cometeram crimes. 
A desatenção para com as necessidades das mulheres presas faz dos presídios femininos unidades de "segunda linha", ou seja, claramente, reproduzem o lugar de submissão e descaso que as mulheres ainda ocupam em vários setores da sociedade (FARREL, 1998, BECKERMAN, 1994, JOHNSTON, 1995).

As mulheres são diferentes dos homens, mas têm direitos humanos iguais. Não é mais possível ignorar e continuar tratando as questões da criminalidade feminina como "questões de homens". Isso certamente corresponde ao que Fernández (1995) denominou direito de gênero. As mulheres criminosas são hoje condenadas pelos mesmos princípios jurídicos que os homens, mas não podem ser, por suas específicas diferenças de gênero, tratadas da mesma forma.

Uma última intenção que tenho neste texto é introduzir novos elementos às considerações sobre a constituição da subjetividade nas populações que ocupam o espaço das prisões - quer sejam trabalhadores quer internos. Entendo, como Guirado (1987), que o objeto da Psicologia nesses espaços não deve ser o comportamento ou a mente dos sujeitos, mas sim as relações concretas na forma como são imaginadas e simbolizadas por aqueles que as produzem cotidianamente. Dessa forma a subjetividade deve ser entendida como um efeito das relações concretas vividas no cotidiano e no espaço prisional, e não apenas como a interioridade de um indivíduo.

Neste texto apresentarei relatos e reflexões resultantes de minha experiência como pesquisadora numa unidade prisional feminina da cidade de São Paulo no período de 2001 a 2003, os quais têm referência em minha tese de doutoramento ${ }^{2}$ em Psicologia Social, defendida em 2004.

A prisão feminina em que realizei a pesquisa é apresentada não só a partir de suas características físicas como também a partir de exemplos das possíveis relações concretas entre os atores ${ }^{3}$ institucionais - mulheres presas, funcionários, pesquisadores - os quais exemplificam como as subjetividades podem ser construídas ou modificadas por trás das grades.

\footnotetext{
2 Prisioneiras de uma mesma história: O amor materno atrás das grades. Tese de doutoramento defendida em 2004 no Departamento de Psicologia Social - IPUSP/SP, sob orientação da Prof ${ }^{\text {a }}$ Dr $^{\text {a }}$ Ecléia Bosi.

3 O conceito "atores" é entendido aqui a partir da perspectiva apresentada por Marlene Guirado em seu texto Psicologia Institucional, de 1987.
} 


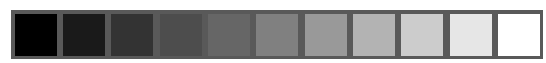

Lopes, R. Memórias de Pesq.: a exp. de uma psicóloga no interior de uma prisão feminina

É possível que algumas mudanças possam ter ocorrido na forma de condução dos assuntos penitenciários desde que terminei o estudo. No entanto, penso que a qualidade das relações produzidas entre as pessoas que ocupam aqueles espaços continua a mesma.

\section{As características, os relatos e as lembranças}

${ }^{4}$ A unidade prisional feminina onde foi realizado o estudo foi desativada e as mulheres, transferidas.
${ }^{5}$ Tive a oportunidade de visitar várias unidades na capital e interior do estado de São Paulo durante o início da pesquisa.

6 Jumbo é o termo utilizado pela população prisional para se referir a um conjunto de provisões entregues por familiares ou amigos nos dias de visitas.
A unidade feminina ${ }^{4}$ era administrada pela Secretaria da Administração Penitenciária de São Paulo e fazia parte de um conjunto arquitetônico que, até 1991, foi utilizado, em sua totalidade, pela FEBEM na aplicação de medidas socioeducativas dirigidas aos adolescentes infratores.

As mudanças introduzidas pelo Estatuto da Criança e do Adolescente e a necessidade de ampliação do número de vagas para mulheres condenadas à pena de privação de liberdade permitiram que - pela ação do Decreto no 34.354 - fosse transferida parte da área construída da Secretaria do Menor para a Secretaria de Segurança Pública e criada a unidade prisional feminina. O restante da área continua, ainda hoje, sendo usada pela FEBEM.

Na primeira vez que entrei naquela penitenciária notei, de imediato, a diferença com relação às demais unidades prisionais, tanto femininas ${ }^{5}$ como masculinas.

O estilo da construção dos prédios era muito distinto daqueles usados para encarcerar adultos nas últimas décadas. Criado de início para adolescentes infratores, foram necessárias várias adaptações ao edifício de forma a adequá-lo ao uso de mulheres adultas.

Foi imediatamente visível que a portaria - onde eram deixados pertences e onde eram entregues os jumbos ${ }^{6}-\mathrm{e}$ as edículas, destinadas à revista dos parentes e amigos nos dias de visita, eram construções mais recentes. 
Os altos muros só existem nas áreas que cercam os pavilhões, mas nem por isso, o aspecto geral era menos hostil e constrangedor. Foi possível ver e sentir o regime de exclusão desde o momento da chegada à unidade.

A necessidade de identificação na portaria é uma regra imutável. Regra de segurança e disciplina. Já a necessidade de explicação de por que se está ali diminui significativamente quando, de certa forma, se passa a fazer parte da paisagem, ou seja, quando os agentes de segurança se habituam com sua presença. Isso aconteceu comigo rapidamente, embora freqüentasse a unidade apenas uma vez por semana. Ao final do primeiro mês de pesquisa era imediatamente reconhecida quando chegava.

Os alambrados que separam as áreas externas da penitenciária daquelas da FEBEM permitiam entrever os funcionários e internos que lá e cá transitavam.

Fui, várias vezes, testemunha silenciosa do caminhar dos jovens internos da FEBEM pelo pátio externo, enquanto, do lado de cá do alambrado - por onde eu caminhava e olhava - sentenciadas varriam o chão absortas em sua atividade, mas fiscalizadas a distância. Parceiros do silêncio, ocupando pátios contíguos da exclusão, da humilhação e da indiferença.

Ao manter um olhar ativo sobre essa realidade pude perceber outras semelhanças entre eles: o olhar vazio e arredio que não buscava mais o conhecimento na mesmice cotidiana, mas, que se mobilizava para o novo: alguém que passava. As posturas compostas de movimentos restritos e previsíveis e a roupa que era usada, que diferenciava quem era funcionário e vigiava de quem era interno e vigiado. Tudo lembrava o rigor das normas disciplinares.

As prisões criam para os internos um mundo em que a mutilação do eu é quase inevitável, como afirmava Goffman (1974). O abandono da vida que levava fora implica não só transformar olhares e posturas mas também adotar comportamentos autômatos além de ter de passar anos tendo sua intimidade violada permanentemente por um contato interpessoal forçado. 


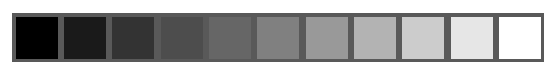

Lopes, R. Memórias de Pesq.: a exp. de uma psicóloga no interior de uma prisão feminina

7 Dados da SAP em 24/10/ 2003. Em 1998, o número na mesma unidade era de 370 presas.
Todos sabiam sem precisar perguntar quem era de fora, quem era de dentro. Eu me sentia como uma estrangeira - talvez invasora embora já tendo estado, tantas vezes, em lugares semelhantes. Estava ali sabia bem por que e sabia mais: que nunca mais seria a mesma.

Numa espécie de subportaria, localizada próxima ao setor de revista, quem adentrava a unidade passava por um detector de metais, mas, mais uma vez a diferença: quando se passa a ser (re)conhecido na unidade, o som que eventualmente disparava - e comigo sempre causado pela presença do gravador - já não indicava um risco depois de um mês. Todos já me identificavam como aquela que conversava com as presas. Se isso, de um lado, facilitava minha entrada, de outro já era uma indicação de minha aderência ao lugar.

Não posso negar que isso me causava certo incômodo, pois queria garantir um distanciamento adequado; todavia, como já tinha percebido, as prisões acabam por produzir relações muito típicas: acentuam - pelas práticas disciplinares - as diferenças entre os presos e os funcionários e naturalizam as que se dão entre os funcionários e aqueles que lá desenvolvem alguma atividade.

A unidade, que tinha capacidade para abrigar 550 internas, mantinha 583 no período da pesquisa ${ }^{7}$ Era formada por seis pavilhões: quatro deles denominados residenciais, um onde estavam localizadas oficinas de trabalho, mas nas quais também existiam celas para o cumprimento de regime de observação e sanções disciplinares, e um último composto de oficinas e celas utilizadas para as visitas íntimas, que ocorriam nos dois últimos finais de semana do mês.

O prédio apresentava vários acessos que levavam aos pavilhões, contudo os funcionários e visitantes - advogados, promotores, juízes, pesquisadores - adentravam a unidade pelo prédio administrativo, o qual tinha dois pavimentos. Em sua parte inferior encontrávamos uma pequena portaria denominada setor de inclusão por onde as mulheres presas entravam quando chegavam à unidade e por onde entravam as visitas familiares nos finais de semana. Esse acesso no pavimento inferior levava diretamente aos corredores internos dos pavilhões. 
Do lado externo do prédio, encontrava-se um acesso, em forma de rampa, que levava ao pavimento superior onde ficavam os setores administrativos propriamente ditos - salas das diretorias, arquivos, setores de atendimento, copa etc. Tanto em sua parte externa como na interna, observa-se que o prédio era mal conservado, apesar da pintura recente nos corredores internos em tom azul - como no melhor dos mundos que a cor azul sugere. O que muitos poderiam caracterizar como um escasso investimento em manutenção me parecia mais fruto do descaso e abandono.

Embora não fosse fácil, era necessário olhar para aquele espaço não como quem vê por ver, mas como quem vê buscando um conhecimento, e então a prisão se revelava como um espaço de (sobre)vivência desprovido, quase que totalmente, de beleza e alegria.

O lugar era mesmo muito feio, de uma feiúra impar, porque lá tudo era absolutamente impessoal. Corredores longos e vazios, mesas de madeira antiga e sem brilho, cadeiras de estofados desgastados, pilhas de papéis. Apesar do azul das paredes, o clima era de um cinza intenso. Nada que fornecesse alguma sensação de calor, aconchego e acolhimento.

A prisão era fria, em todos os aspectos. O vermelho só aparecia nos papéis que enfeitavam as raras festas ou nos dramáticos momentos de revolta.

O pé-direito da construção era baixo e somente as salas posicionadas na direção do pátio externo possuíam iluminação natural. Nos corredores e demais salas a iluminação era ampliada por um sistema de clarabóias protegidas por domo leitoso.

A ventilação, de modo geral, era insuficiente contribuindo para ampliar, nos dias de maior temperatura, o sentimento de opressão típico das prisões. Para muitas mulheres que passaram sua infância na roça, o frescor do ar matinal era apenas uma distante lembrança.

No centro do primeiro corredor da administração, encontrava-se, à esquerda, a chefia de plantão. Nesse setor controlava-se a movimentação de pessoas entre o prédio administrativo e os pavilhões. Entre 


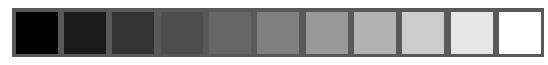

Lopes, R. Memórias de Pesq.: a exp. de uma psicóloga no interior de uma prisão feminina

dois grandes portões de ferro, um pequeno espaço de circulação denominado apenas por "acesso". Por ali passavam inúmeras pessoas durante o dia. Um canal estreito, ponto de fortes tensões. Era para esse local que afluíam as queixas, as solicitações, as mágoas e as revoltas. Era esse o ponto final que marcava a divisão entre o mundo externo e o mundo das internas.

Nesse local vivi uma das experiências mais marcantes do tempo de pesquisa. Naquele dia, poucas agentes de segurança compunham o grupo de vigilância responsável pelo controle da circulação das sentenciadas e também o meu. Eu realizava as entrevistas em uma sala da escola que ficava no piso inferior do prédio da administração, e para chegar até lá tinha que atravessar alguns portões.

O acesso a essa sala era possível a partir do ponto nevrálgico - o pequeno corredor do acesso. Estávamos lá, pelo menos seis mulheres diferentes, alvoroçadas diante de um portão - canal aberto entre o fora e o dentro -, cada uma com uma necessidade diferente. Havia um clima de tensão no ar. É bem verdade que esse clima é uma constante na prisão, mesmo em dias de calmaria, mas naquele dia nada estava calmo ali.

Eu queria me encontrar com as pessoas que tinha agendado e toda aquela confusão estava me deixando muito irritada. Sem pensar muito nos riscos, querendo resolver meu problema e facilitar para as funcionárias, perguntei se não poderia descer sozinha. Ela me olhou um tanto surpresa e, talvez querendo se livrar de mais uma ocupação, disse que se eu não via problemas, poderia ir. O que sucedeu a esse acordo foi marcante para mim.

Fiquei momentaneamente paralisada com a autorização, mas não tive coragem de voltar atrás. Ela me entregou um molho de chaves e foi logo informando de onde eram, como deveria fechar o portão depois que passasse por ele, me orientando que não abrisse para qualquer presa e eu, meio atônita, apenas ouvia.

Assim que terminaram as recomendações, a agente deixou-me onde estava e foi resolver outros problemas. Eu fiquei parada por poucos segundos. Olhei para a direção a seguir e dei o primeiro 
passo. Nunca tinha ficado com as chaves da cadeia nas mãos ${ }^{8}$. Ter as chaves dos portões de uma prisão nas mãos é indicativo de poder, um poder de conceder acesso, abrir e fechar portas, controlar movimentos, diálogos e trocas, um poder historicamente masculino e que atualmente também é exercido por mulheres que trabalham como agentes de segurança.

Na frente do portão, já não sabia qual era a chave correta para abrilo. A momentânea identificação com a função se revelou improdutiva. As informações foram passadas tão rapidamente que não tive tempo de absorvê-las. Eu tinha de abrir um portão, tinha a chave, mas era uma presa da ignorância e da inexperiência. Instantes de angústia até finalmente abrir o portão. E que alívio quando o fechei atrás de mim! Porém, eu estava literalmente trancada num espaço que não conhecia. Tinha um poder, mas era presa do não-saber.

O que eu sentia era um misto de medo, ansiedade e expectativa. Dirigi-me até a sala da escola e lá fiquei aguardando algum sinal que indicasse a presença de alguma das mulheres com as quais conversaria.

Depois da primeira, uma após outra repeti o mesmo ritual: subia a escada, abria o portão, despedia-me, trocava olhares com as outras mulheres que estavam na galeria e, rapidamente, fechava o portão. Naquele dia, além de psicóloga e pesquisadora estive como agente de segurança, momentos em que pude sentir o quanto de alienação é produzida nessa atividade autômata. Um automatismo defensivo, talvez, pois pude sentir como é difícil manter a consciência permanentemente atenta nesses gestos de trancar e soltar pessoas. Fiquei nessa dupla atividade por volta de três horas. Ao final, tive de fazer o caminho de volta ao mundo exterior.

Era meio-dia quando atravessei a galeria e cheguei ao portão que me permitiria acesso ao setor administrativo. A galeria estava relativamente tranqüila e vazia. Lugar de intensa movimentação de presas durante o período da manhã e da tarde, essa galeria era conhecida como Rua Direita, porém no horário do almoço o movimento era pequeno. Poucas presas estavam próximas ao portão do acesso e percebi que me olhavam com certa curiosidade.
8 Essa é uma expressão muito típica no universo prisional e utilizada, regularmente, pelos agentes de segurança penitenciária. 
Ao chegar em frente ao portão, ele estava fechado. Bati algumas vezes, em vão. Parecia estranho não obter resposta para algo aparentemente tão normal. Descobri que na prisão nem tudo é o que parece. Ninguém abria o portão para me livrar daquela situação insólita.

O pouco tempo que permaneci ali parada e constrangida pareceume uma eternidade. Percebi que minha situação chamava a atenção das presas e eu não sabia por quê. Bati mais algumas vezes no portão até que uma presa se aproximou e me disse: - "Olha doutora, desse jeito ninguém vai abrir não! Tem que fazer assim...”. E, usando uma caneta que tinha na mão, ela arranhou a grade da pequena janelinha de observação que existia no alto do portão e, ao fazer esse movimento, produziu um forte ruído.

Rapidamente, para minha surpresa, uma agente abriu a janelinha, olhou para mim e perguntou: "Que você quer?". "Entrar", respondi. Para minha surpresa ela perguntou: "Quem é você?". Minha resposta foi imediata: "psicóloga". Ela me olhou desconfiada, mas outra agente, lá do fundo do corredor, veio em meu socorro dizendo: "Deixa a moça entrar, ela é psicóloga mesmo!".

Essa experiência me possibilitou, mesmo que por breves momentos, experimentar a mesma dor daquelas mulheres que no interior das prisões se tornam números, apelidos desqualificativos, pessoas sem nome e sem uma identidade reconhecida, mulheres que não são percebidas em sua singularidade, são mais uma na multidão que transita.

Naquele mundo de relações ambíguas não fui reconhecida por aquela que, como eu, estava ali desenvolvendo um trabalho, pois mesmo tendo usado um título de relativo poder no lugar para me apresentar, nada em mim me destacava do grupo.

Do lado de lá do portão, eu era apenas mais um rosto, colado à janelinha do portão, pedindo para entrar. Foi forte a emoção de parecer, mesmo que por um breve instante, uma mulher presa, um rosto em meio a tantos outros, alguém, como tantas outras, pedindo qualquer coisa, ou mesmo zombando ao dizer que era psicóloga. 
Porém, do lado de cá do portão fui identificada na minha singularidade, fui percebida como alguém que não pertencia ao grupo, mas que, estranhamente, desconhecia o gesto que levaria à abertura do portão. Sem se deter nos porquês de meu comportamento estranho, aquela mulher veio em minha direção e me ajudou. Ao conceder-me a senha de acesso oportunizou-me fazer o caminho de volta.

Essa não foi a única vez que eu andei pela galeria principal do presídio feminino. Em outras oportunidades experimentei aqueles sentimentos confusos, uma mistura, nada homogênea, de medo, ansiedade, expectativa. O coração batendo mais forte, a fala precipitada em perguntas banais buscando aliviar a tensão e o caminhar apressado de quem quer evitar contatos não programados, já que também não havia tempo para isso.

Para quem está livre, vivendo o dinamismo do século XXI, a vida se processa em coordenadas espaço-temporais que não guardam nenhuma relação com aquelas vividas por quem está preso.

Para os cidadãos livres, os espaços são cada vez maiores e o tempo cada vez menor. Quase nunca temos tempo para conversar com amigos, caminhar no fim da tarde ou ler um livro sem compromisso.

Já os encarcerados, por contraste, são aqueles para os quais não há qualquer espaço, suas vidas são vividas em celas diminutas durante anos seguidos. Mas o tempo, embora não pare, parece infinito, assim como infinitas são as dores de vivê-lo atrás das grades.

O fluxo frenético das sentenciadas na galeria principal que reproduzia a vida urbana em seu cotidiano talvez ocultasse a busca do espaço perdido e o esquecimento do tempo ganho. Porém, a busca de contato, nessas ocasiões, mesmo que breve, sempre revelava a básica necessidade humana de comunicação.

A unidade feminina era, como já mencionei, formada de seis paviIhões, edificações de dois andares, além do térreo. Nos pavilhões encontrava-se, ao mesmo tempo e no mesmo espaço, a casa, o 


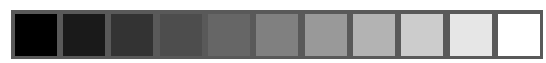

Lopes, R. Memórias de Pesq.: a exp. de uma psicóloga no interior de uma prisão feminina

9 Pedra é o nome dado à cama de alvenaria em que os presos (as) dormem. A referência, apesar de apresentar certa crueza, é em muitos sentidos real, especialmente porque os colchonetes utilizados nas prisões isolam precariamente o frio da cama de alvenaria.

10 Nesta unidade existiam celas menores para apenas três mulheres. No entanto, devido à superpopulação, as maiores chegavam a abrigar até sete.

450 barraco, a pedra ${ }^{9}$, o lugar de trabalho, em que se obtinha o complemento para o sustento da família que estava lá fora, o lugar do castigo, nas celas solitárias, e os pátios, nos quais eram realizadas as festas do Dia das Mães, do Natal e do Ano-novo.

Nos pavilhões vivia-se a coletividade forçada. Partilhavam a casa/ cela com outras mulheres inicialmente desconhecidas que, com o passar dos anos, se tornavam mais uma da família. Num espaço mínimo, com ventilação e iluminação precárias, viviam, em média, cinco mulheres ${ }^{10}$. A primeira vez que entrei nos pavilhões para visitar "a casa" das mulheres presas foi também a primeira em que pude ver alguma beleza na prisão.

Quase todas as celas são decoradas. Uma decoração simples, no estilo casa de boneca. Nelas vi cortinas feitas de barbantes com motivos florais e geométricos, as quais separavam os pequenos espaços de intimidade absoluta - as camas.

Nas cabeceiras das camas pequenos armários feitos de caixas que eram, em sua maioria,, forradas com papéis coloridos. Neles eram guardados os pertences pessoais possíveis de serem mantidos no mundo da prisão - xampu, sabonete, pasta e escova de dentes, alguma bijuteria, cartas e fotos além de pequenas bonecas feitas pelas próprias presas e que conferiam ao espaço certa alegria.

Algumas mulheres decoravam as paredes com fotos de ídolos ou santos de devoção, símbolos do imaginário. O que não faltavam nas celas eram rádios e televisões. Embora considerados elementos de conexão mais imediata com o meio social, mostravam-se, na verdade, como tristes paliativos contra a opressão e a solidão. Em algumas moradias, cheguei a ver mais de uma TV, as quais eram colocadas na beirada da cama. Perguntei como faziam quando mais de uma ligava o aparelho ao mesmo tempo e ouvi que isso "não era problema", quando não queriam ver o mesmo programa, elas simplesmente "davam um jeito".

Outro armário no pequeníssimo corredor da cela ou mesmo uma cama desocupada podia acabar sendo transformada em uma espécie de dispensa coletiva na qual eram guardados alimentos - 
geralmente bolachas, pão de forma, enlatados e refrigerantes trazidos pela família ou mesmo comprado por elas. No meio da cela, separando dois grupos de camas, a privada, quase sempre ocultada por uma cortina.

Muitas habitantes das casas-celas que visitei me ofereciam biscoitos ou um copo de refrigerante, gentileza tão comum entres as mulheres que se sentem satisfeitas ao receber uma visita em sua moradia.

Algumas me perguntavam se tinha gostado da casa delas, outras comentavam o quanto demoravam para lavar e encerar o piso pintado de vermelho, outras repetiam várias vezes sobre o como eram boas crocheteiras, outras reclamavam da falta de cuidado de algumas na higiene dos banheiros coletivos, mas todas, sem exceção, me convidaram para voltar outras vezes.

Quando me lembro do tamanho da cela ainda fico impressionada com a capacidade de adaptação que essas mulheres demonstraram. Mesmo que levemos em consideração que num presídio a vida é uma constante experiência de frustração e dor, essas mulheres literalmente extraíam da pobreza absoluta de recursos do lugar a beleza possível e, de si mesmas, a tolerância imprescindível para a convivência inevitável.

Em muitas casas fui recebida por um casal. Uma das presas era apresentada como o marido e a outra como esposa. Enquanto uma se responsabilizava pelo cuidado e conservação da casa, a outra trabalhava em oficinas para garantir as necessidades das duas. Numa reprodução de um casamento burguês, os lugares estavam bem definidos pelas funções que cada uma tinha a desempenhar.

Em outras, embora essa parceria amorosa homossexual não fosse tão francamente exposta, era possível supô-la após algum tempo de conversação. O pudor observado nesses contatos, como descobri mais tarde, referia-se à necessidade de não tornar explícita uma relação movida apenas por interesses circunstanciais.

A parceria amorosa homossexual, embora não oficialmente autorizada, é bastante freqüente nas prisões femininas, e os contatos 


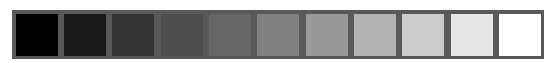

Lopes, R. Memórias de Pesq.: a exp. de uma psicóloga no interior de uma prisão feminina

sexuais são mantidos no espaço reservado das casas-cela onde elas residem.

As mulheres heterossexuais atendiam suas necessidades sexuais das formas mais diversas e ocultas até o início de 2002, época em que foi implantado o Programa de Visita Íntima nas prisões femininas.

Ainda que a gravidez possa ser um resultado desses contatos, essa unidade não contava com alojamento para mães e futuros bebês. Quando isso ocorria a futura mãe permanecia na unidade até a época do parto e, após o nascimento do bebê, mãe e filho(a) eram transferidos para alguma outra unidade que possuía alojamento específicos para a dupla aproximadamente durante quatro meses.

Os pátios eram os espaços reservados para os encontros que envolviam um maior número de pessoas. Neles ocorriam as festas, as apresentações de cantores e atores, as práticas de jogos, os encontros familiares nos dias de visita, mesmo local onde são lavadas e estendidas as roupas durante os dias úteis da semana.

Não existem muitas opções de atividades nas prisões, e a circulação se faz, de maneira regrada, nos mesmos lugares - oficinas, escola, celas, banheiros, pátios, enfermaria, administração. Delineando a imagem de um circuito fechado, os relacionamentos na prisão sugeriam a urgência de oxigenação e do alívio das dores de viver no tempo presente. A única saída dessas mulheres me pareceu rememorare sonhar.

As mulheres podiam trabalhar nas oficinas, na administração, em serviços de manutenção ou ainda nas próprias celas. Nem todas tinham oportunidade de trabalhar, e essa situação gerava importantes conflitos. As que não tinham apoio da família nem trabalho eram as que sofriam os piores tipos de carência material. Para muitas, o trabalho na prisão representava um complemento no orçamento familiar.

Em todos pavilhões, existiam oficinas de trabalho no primeiro andar. Era possível caminhar por várias delas atravessando os corredores que interligavam os diferentes pavilhões, porém o acesso a elas 
pelas mulheres presas se fazia, exclusivamente, pelos andares térreos dos pavilhões 2 e 5 .

Visitei algumas oficinas de trabalho e pude ver de perto mulheres produzindo desde pratos de papelão, língua-de-sogra e roupas até componentes eletrônicos, alto-falantes para carros, relógios de hidrômetros e telefones. Envolvidas nessas atividades estavam pelo menos $40 \%$ das internas.

Algumas mulheres - geralmente as que tinham um melhor nível de instrução - trabalhavam nos setores administrativos suprindo a carência de funcionários, o que era uma constante nas prisões à época. Outras atuavam em serviços de manutenção da unidade - limpeza, distribuição de alimentos, coleta de lixo - ou ainda na enfermaria.

As mulheres que não se inseriam nesses trabalhos formais buscavam seu sustento em atividades artesanais, sendo que algumas chegam a se organizar num esquema que lembra as cooperativas. Os produtos - tapetes, almofadas, bichos de pelúcia, blusas de tricô e crochê, objetos decorativos, bonecas etc. -, eram vendidos não só pelos seus familiares, mas também pela Fundação de Amparo ao Trabalhador Preso - FUNAP.

As prisões se constituem num grande pólo produtor de bens de consumo. Até algum tempo atrás, não havia uma regulamentação para o pagamento dos serviços prestados por essas mulheres, o que só ocorreu em 2002. No entanto, os direitos legais, tais como aposentadoria, seguro saúde, fundo de garantia, não são extensivos ao trabalhador preso.

Alguns poderiam dizer que, se esses direitos não são garantidos a muitos trabalhadores da sociedade, por que deveriam ser aos presos? Multiplicam-se as injustiças sociais enquanto, todos os dias, aqueles que instalam suas oficinas nas prisões se livram das despesas de contratação de um trabalhador.

As prisões podem ser descritas a partir de diferentes ângulos. Apresentei uma visão que traz em alguma medida minha aproximação afetiva do cotidiano de uma prisão e das mulheres com quem convivi durante o tempo de pesquisa. 


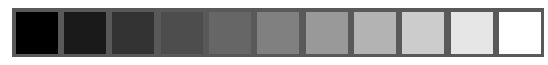

Lopes, R. Memórias de Pesq.: a exp. de uma psicóloga no interior de uma prisão feminina

É possível admitir que outras unidades prisionais femininas apresentem características semelhantes às que descrevi. No entanto, é também possível supor que cada uma delas, ao seu modo, cria um mundo particular para o grupo de mulheres que lá habitam e que assim, outros "olhares" possam exprimir fatos que não fui capaz de capturar na pesquisa que realizei.

Veras, Marias, Ângelas, Cristinas, Andréias, Simones, Cibeles, Márcias, Cláudias e tantas outras. Mulheres com as quais pude trocar tantas experiências e que me permitiram perceber o quão pouco sabemos sobre suas vidas e das transformações que sofrem a partir da experiência na prisão durante os longos anos de suas penas.

O que na realidade importa é o compromisso que podemos ter - ou desenvolver - diante dessas experiências humanas. Subjetividades que se desenvolvem - porque a vida é processo incessante acreditando que o amanhã é algo possível, embora o presente seja desanimador.

No espaço das prisões, o binômio público-privado sofre um redimensionamento. Lá ocorre um predomínio absoluto das atividades públicas, coletivas, e aquilo que entendemos como privado ou íntimo fica quase restrito à cela, e mesmo nela, diante da companheira desconhecida, há que se produzir um recuo da espontaneidade. $O$ que é singular, íntimo e particular a cada uma fica adstrito à sua cama, ao seu sono ou, nos piores casos, a uma realidade particular e ilusória, construída como defesa. Nas prisões observei um esmagamento do que se entende por âmbito privado.

Como num caleidoscópio são produzidas novas formas de impressões, sensações e relações. Numa realidade de exclusão pública ou de privacidade compartilhada as referências anteriores são rapidamente substituídas, quando não abandonadas. Cria-se um novo mundo real, de experiências concretas, regras definidas e espaços demarcados.

Os muros de uma prisão são mais do que fatos físicos que isolam um espaço exterior de um espaço clausural. Metaforicamente, as 
sombras desses muros projetam-se nos interiores das pessoas que lá vivem e isolam ilhas potenciais de amor e amizade.

Em meio a todas essas misérias, a tendência dominante é esperança virar sinônimo de Deus. Deus passa a ser mais do que um ser metafísico que transcende tudo e que é material e temporal. Deus, para essas mulheres, não é imaterial e atemporal, é o futuro concreto que lhes permite admitir a materialização de suas esperanças. Em outras palavras, Deus é o passaporte para a felicidade.

Penso que os estudos realizados no âmbito das prisões femininas, ainda que insuficientes na realidade brasileira, têm sido um alerta para que as autoridades do setor reconheçam a necessidade de mudar. No entanto, em virtude de uma lógica que privilegia os problemas relativos ao encarceramento de homens, estatisticamente mais expressivo, as questões referentes às mulheres que se encontram nas mesmas condições têm sido relegadas a um segundo plano.

É necessário admitir como insuficiente as discussões em torno da problemática das prisões femininas e buscar alternativas para as necessidades das mulheres que estão presas. Os profissionais comprometidos com a mudança social e com avanços no sentido da garantia dos Direitos Humanos a essas populações precisam ampliar as reflexões sobre as "penas adicionais" que são impostas às mulheres presas, redimensionar nossas perspectivas de atendimento e, acima de tudo, atuar politicamente na construção de uma sociedade mais justa e igualitária.

Resumo: O texto apresenta as reflexões de uma psicóloga e pesquisadora a partir de sua experiência numa unidade prisional feminina da cidade de São Paulo no período de 2001 a 2003, época em que colhia dados para elaboração de sua tese de doutorado no Instituto de Psicologia da Universidade de São Paulo. Os fatos apresentados neste texto relatam algumas de suas experiências durante o tempo da pesquisa, especialmente no que se referem ao impacto que a instituição prisional exerce sobre aqueles que lá desenvolvem atividades 


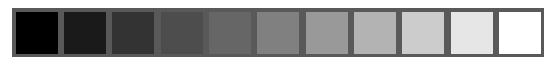

Lopes, R. Memórias de Pesq.: a exp. de uma psicóloga no interior de uma prisão feminina

como também, e principalmente, sobre os que lá cumprem pena. As reflexões produzidas têm como referência autores do Direito, da Sociologia, da Psicologia e da Criminologia. O texto tem por objetivo sensibilizar o leitor sobre os efeitos que as prisões têm sobre a mente humana. Como um texto que privilegia a temática do gênero feminino, aponta para o descaso com que as questões das mulheres encarceradas são tratadas no âmbito da política penitenciária nacional.

Palavras-chave: prisões femininas, gênero, política penitenciária.

\begin{abstract}
The text shows the reflections of a psychologist and researcher from her experience in a women's prison unit from 2001 to 2003 in the city of São Paulo, the period during which she collected data to elaborate her Doctor's Degree Dissertation for the Psychology Institute of the São Paulo University.

The facts presented in this text report some of her experiences during her research time, specially regarding the impact that a prison institution exerts on those people who develop activities there, as well as, and mainly, on those who were sentenced.

Law, Sociology, Psychology and Criminology Authors have been used as references to the reflections developed. The text's purpose is to make the reader sensitive with the effects that prisons have over the human mind. Characterized as a text that privileges the female gender's theme, it points towards the disregard with which the imprisoned women's matters are treated within the scope of the national penitentiary policy.
\end{abstract}

Key words: women's prisons, gender, penitentiary policy. 
Resumen: El texto presenta las reflexiones de una psicóloga e investigadora partiendo de su experiencia en una unidad de prisión femenina de la ciudad de San Pablo, de 2001 a 2003, época en que recogía datos para la elaboración de su tesis de doctorado en el Instituto de Psicología de la Universidad de San Pablo (USP). Los hechos presentados en este texto relatan algunas de sus experiencias durante el periodo de la investigación, especialmente las que se refieren al impacto que la institución de detención ejerce sobre quien en su interior desarrolla actividades como también, y principalmente, sobre quien está cumpliendo pena. Las reflexiones producidas tienen como referencia autores de Derecho, de Sociología, de Psicología y de Criminología. El texto tiene por objetivo sensibilizar los lectores sobre los efectos que prisiones tienen sobre la mente humana. Como un texto que privilegia la temática del género femenino, él señala para la dejadez con que las cuestiones de las mujeres que están en la cárcel son tratadas en el ámbito de la política penitenciaria nacional.

Palabras clave: prisiones femeninas, género, política penitenciaria.

Bibliografia

ARÚS, F. B. La mujer y el sistema penitenciario español. In: Poder Judicial, Madrid, n.39, p.65-97, set.1995.

BECKERMAN, A. Mothers in prison: meeting the prerequisite condictions for pregnancy planning. In: Social Work, EUA, v.39, 1994.

BIERRENBACH, M. I. Sistema Penitenciário - A mulher presa. In: Revista do llanud, São Paulo, n.12, p. 71- 82, 1998.

FARRELL, A. Policies for Incarcerated Mothers and their families in Australian Corretions. In Australian and New Zealand Journal of Criminology. Queensland, Australia, n.31, p.101-117, 1998. 


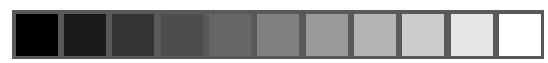

Lopes, R. Memórias de Pesq.: a exp. de uma psicóloga no interior de uma prisão feminina

FERNÁNDEZ, G. T. Mujer, Cárcel y Derechos Humanos. In: Capitulo Criminologico, Maracaibo, Venezuela, v.23, n.1, p.337-358, enero/ junio, 1995.

FOUCAULT, M. Vigiar e Punir - Nascimento da Prisão. Tradução de Ligia M. Pondé Vassallo. Petrópolis: Vozes, 1977. 275p.

. Microfísica do Poder. Organização e tradução Roberto Machado. 4. ed. Rio de Janeiro: Graal, 1984. 295p.

A Verdade e as Formas Jurídicas. Tradução Roberto Cabral de Melo Machado e Eduardo Jardim Morais. Rio de Janeiro: Nau Ed., 1996. 160p.

GOFFMAN, E. Estigma: Notas sobre a Manipulação da Identidade Deteriorada. Tradução de Márcia Bandeira de Mello Leite Nunes. Rio de Janeiro: Zahar, 1975.158p.

GOFFMAN, E. Manicômios, Prisões e Conventos. Tradução de Dante Moreira Leite. São Paulo: Perspectiva, 1961.315p.

GRAZIOSI, M. Infirmitas sexus: la mujer en el imaginario penal. In: Nueva Doctrina Penal, Buenos Aires, p. 55-95, 1999.

GUIRADO, M. Psicologia Institucional. São Paulo: EPU, 1987. 133p.

JOHNSTON, D. Jailed mothers. In: Gabel, K e Johnston, D. (ed.) Children of incarcerated parents. New York: Lexington Books, 1995. 252p.

LAQUEUR, T. Inventando o Sexo - Corpo e Gênero dos Gregos a Freud. Tradução Vera Whately. Rio de Janeiro: Relume Dumará, 2001. $313 p$.

LOPES, R. Prisioneiras de uma mesma história: O amor materno atrás das grades. 2004. 268f. Tese (Doutorado em Psicologia Social) Instituto de Psicologia, Universidade de São Paulo, São Paulo, 2004.

PARENT, C. La protection chevaleresque ou les représentationsmasculines du traitement des femmes dans la justice pénale. In: Déviance et Société, Liège, v.10, n.2, p. 147-175, 1986.

ROCHA, L. C. A Prisão dos Pobres. 1994. 279 f. Tese (Doutorado em Psicologia Social) - Instituto de Psicologia, Universidade de São Paulo, São Paulo, 1994.

ROSALDO, M. Z.; LAMPHERE, L. A Mulher, a Cultura e a Sociedade. Tradução de Cila Ankier e Rachel Gorenstein. Rio de Janeiro: Paz e terra, 1979. 254 p. 


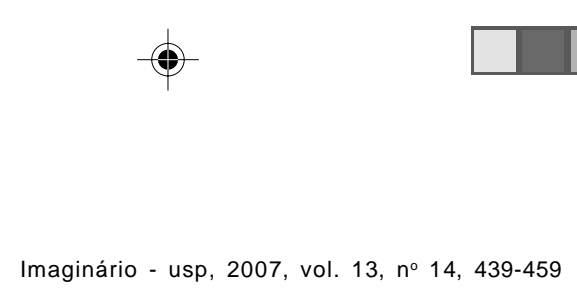

SAFFIOTI, H. I.B. Rearticulando Gênero e Classe Social. In: COSTA, Albertina de Oliveira \& BRUSCHINI, Cristina. Uma Questão de Gênero. Rio de Janeiro: Rosa dos Tempos. São Paulo: Fundação Carlos Chagas, 1992. p.183-251.

; MUÑOZ-VARGAS, Mônica. Mulher Brasileira é Assim. Rio de Janeiro: Rosa dos Tempos, NIPAS, Brasília: UNICEF, 1994.283p.

SALLA, F. As Prisões em São Paulo: 1822 - 1940. São Paulo: AnnaBlume, 1999. 371p.

SMAUS, G. Teoría del conocimiento feminista y criminología de la mujer. Revista Brasileira de Ciências Criminais, São Paulo, ano 7, n.27, p. 235-249, jul./set. 1999.

e-mail: rosecastle@directnet.com.br Recebido em 19/08/2006. Aceito em 20/09/2006. 


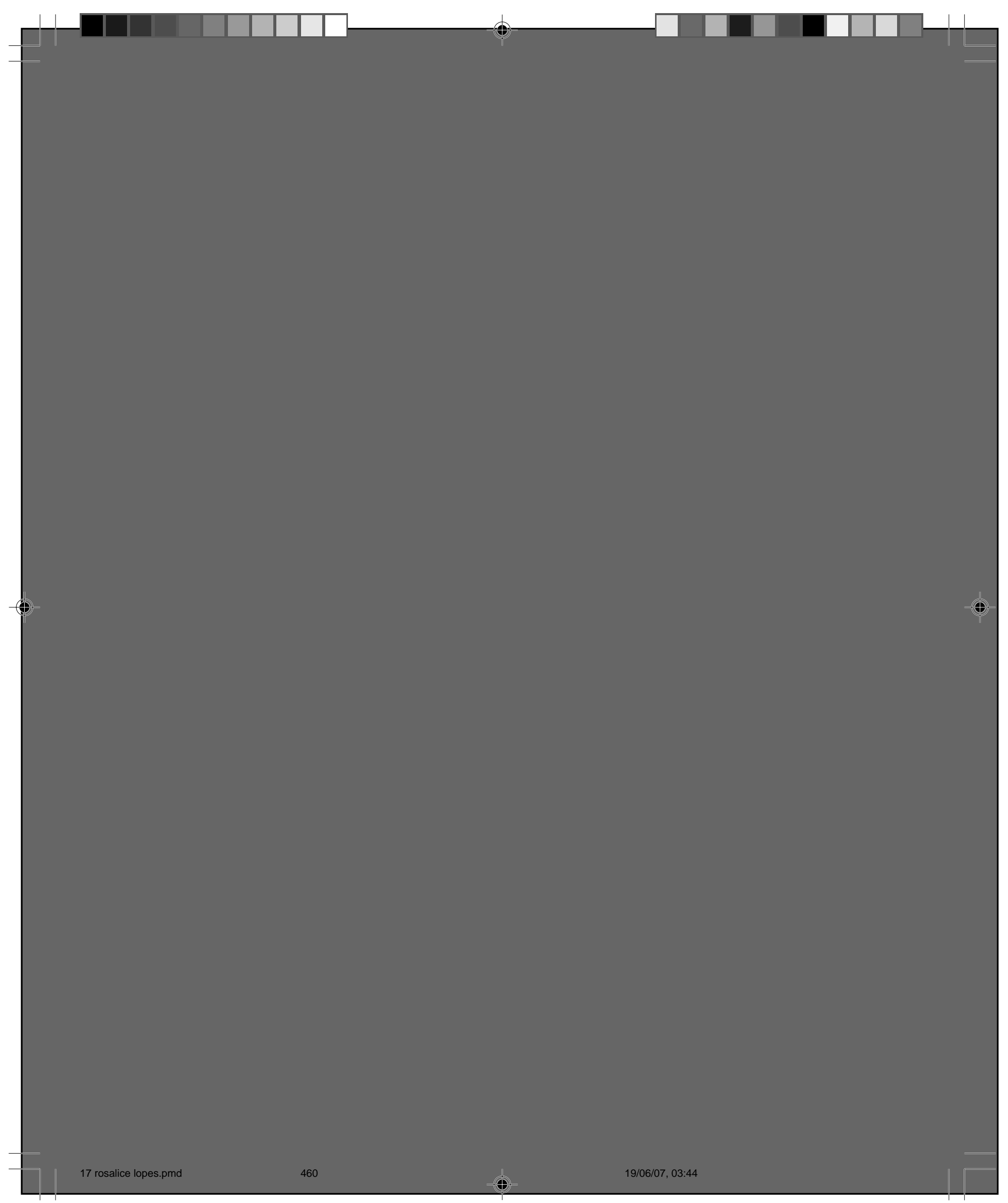

